\title{
Comparative Analysis of Nasal Smear Eosinophilia and Serum IgE Levels for the Diagnosis of Allergic Rhinitis
}

\author{
Samina Qamar ${ }^{1}$, Nukhbatullah Awan ${ }^{1}$, Khalid Munir Cheema ${ }^{1}$, Nadeem Raza ${ }^{1}$, Sobia Ashraf ${ }^{1}$ and Abdul Rehman ${ }^{2}$ \\ ${ }^{1}$ Department of ENT, Mayo Hospital / KEMU, Lahore, Pakistan \\ ${ }^{2}$ Department of Pathology, Mayo Hospital / KEMU, Lahore, Pakistan
}

\begin{abstract}
Objective: To compare and determine the sensitivity, specificity, positive predictive value (PPV) and negative predictive value (NPV) of nasal smear eosinophilia and serum IgE levels for the diagnosis of allergic rhinitis (AR).

Study Design: Analytical study.

Place and Duration: ENT and Pathology Departments, KEMU/Mayo Hospital, Lahore from January 2018 to December 2019.

Methodology: Two hundred and twenty-one patients presenting with recurrent rhinitis were included in the study. They were divided into two groups: group 1 presented with history suggestive of allergy for more than four weeks and confirmed to be AR on skin prick tests; group 2 patients with negative skin prick tests taken as controls. Both groups were subjected to serum IgE levels and nasal smear for eosinophilia. Prick test was taken as gold standard, and $p<0.05$ was taken statistically significant.

Results: One hundred and twenty-one patients diagnosed as allergic rhinitis on skin prick tests in group 1 and 100 patients as controls in group 2 had negative skin prick tests. Ninety-one (75.2\%) patients had AR on nasal smear eosinophilia in group 1 and $89(73.6 \%)$ patients had AR on serum IgE levels in group 1. Sixty-eight patients (56.2\%) were males and $53(43.8 \%)$ were females in group 1. In group 2, $51(51 \%)$ were males and $49(49 \%)$ were females. Mean difference in nasal smear eosinophil count and serum IgE levels in AR and control group was statistically significant $(p<0.001)$. Sensitivity, specificity, PPV and NPV of nasal smear eosinophilia was $77.8 \%, 71.2 \%, 75.2 \%$, and $74 \%$; and of IgE level was $82.4 \%, 71.7 \%, 73.6 \%$, and $81 \%$, respectively.

Conclusion: Serum IgE and nasal smear eosinophilia levels are helpful in diagnosing allergic rhinitis; however, serum IgE level has better sensitivity and higher NPV than smear eosinophilia. Specificity of both tests is comparable.
\end{abstract}

Key Words: Allergic rhinitis, Nasal smear eosinophilia, Serum IgE level.

How to cite this article: Qamar S, Awan N, Cheema KM, Raza N, Ashraf S, Rehman A. Comparative Analysis of Nasal Smear Eosinophilia and Serum IgE Levels for the Diagnosis of Allergic Rhinitis. J Coll Physicians Surg Pak 2020; 30(12):1297-1300.

\section{INTRODUCTION}

Allergic rhinitis (AR), an IgE mediated hypersensitivity reaction of nasal mucosa, is a common disease entity recognised globally with a worldwide reported prevalence of $10-30 \%$ in adults and up to $40 \%$ in children. ${ }^{1,2}$ Allergic rhinitis and associated comorbidities represent a considerable burden on both society and individual in terms of associated comorbid conditions, health resources, and cost on treatment. ${ }^{3}$ Allergic rhinitis can impair quality of life significantly. ${ }^{4}$

Allergic rhinitis is a systemic illness which is usually associated with headache, fatigue, malaise and tiredness. Common symptoms of presentation are itching in nose, sneezing, rhinorrhea, post-nasal drip, headache, and nasal obstruction. ${ }^{5}$

Correspondence to: Dr. Samina Qamar, Department of ENT, Mayo Hospital / KEMU, Lahore, Pakistan

E-mail: samnir3@gmail.com

Received: June 20, 2020; Revised: September 19, 2020;

Accepted: November 24, 2020

DOI: https://doi.org/10.29271/jcpsp.2020.12.1297
Non-allergic rhinitis is usually difficult to differentiate from allergic rhinitis because of lack of diagnostic criteria, overlap of symptoms. It is important to differentiate AR from non-allergic rhinitis for proper management of various types of rhinitis. ${ }^{6}$

Diagnosis ofallergic rhinitis is based on history and typical examination findings like, clear rhinorrhea, pale bluish tinged nasal mucosa, consistent with an allergic cause along with one or more of the symptoms of AR such as nasal congestion, runny nose, itchy nose and recurrent sneezing, and a variety of laboratory investigations. The latter include nasal smear eosinophilia, serum IgE levels, specific IgE levels and skin prick tests; out of which, skin prick test is considered to be gold standard for allergic rhinitis. $^{7}$

Guidelines for diagnosis of allergic rhinitis suggest that diagnosis should be made when history and physical findings are positive, as skin prick tests and specific IgE levels are expensive and invasive. Non-invasive and less expensive tests, such as nasal smear for eosinophil and serum IgE levels, are well known investigations to confirm diagnosis of AR. Specific laboratory testing (blood or skin) should be performed for patients with a clinical diagnosis of $A R$, who do not respond to empiric treat- 
ment, when diagnosis is uncertain, or when determination of specific target allergen is needed. ${ }^{8}$ Individuals with AR should be assessed for the presence of associated allergic conditions such as asthma, atopic dermatitis, sleep-disordered breathing, conjunctivitis, rhinosinusitis and otitis media. ${ }^{9}$

This study was conducted to determine whether a good clinical examination with typical findings and non-invasive investigations are sufficient to diagnose allergic rhinitis or further laboratory investigations are required to prove it.

The aim of this study was to compare the nasal smear eosinophilia and total serum IgE levels, keeping skin prick test as gold standard, in terms of sensitivity, specificity, PPV and NPV of these two methods.

\section{METHODOLOGY}

This analytical analysis was conducted at ENT Department in collaboration with the Pathology Department, Mayo Hospital, Lahore from January 2018 to December 2019, after obtaining ethical approval from the University. Consecutive purposive sampling technique was used. Patients were divided into two groups. In group 1, patients who presented with history of recurrent sneezing, rhinorrhea, post-nasal drip, nasal obstruction, itching in nose or eyes and palatefor more than four weeks (presence of two or more symptoms according to ARIA classification) with typical physical signs on examination of nose, i.e. bluish tinge, were included. Allergic rhinitis was confirmed by skin prick tests. In group 2, patients were included who had history of recurrent rhinitis butskin pricktestswere negative. Theirlaboratory investigations, including nasal smear eosinophilia and serum IgE levels, were noted from medical records. Patients with history of bilateral permanent nasal obstruction, deviated nasal septum, external deformity of nose or history of trauma to nose, and patients taking topical nasal steroids were excluded.

To collect the nasal samples, a sterile swab was passed along the inferior turbinate, and the specimen was collected on a clear glass slide. Staining with hematoxylin and eosin was done and nasal smears were examined under a microscope. Number of eosinophils per high-power field was counted and smear was considered positive for eosinophilia with more than three eosinophils in each high power field. Serum IgE levels were measured in $\mathrm{IU} / \mathrm{ml}$ and level of $\mathrm{IgE}$ more than $150 \mathrm{IU} / \mathrm{ml}$ was considered positive.

Patients with nasal smear eosinophilia (more than three eosinophils per high power field) and high serum IgE level (more than $150 \mathrm{lU} / \mathrm{ml}$ ) were labelled as investigation confirmed allergic rhinitis.

Statistical analysis was done by SPSS version 22 . The mean values and standard deviation of serum IgE and eosinophils in group 1 and 2 along with mean difference in values of both the groups were obtained and tabulated using independent sample t-test. For quantitative variables like age, IgE levels and smear eosinophil count, mean and standard deviations were calculated; while for qualitative variables like gender, frequencies and percentages were calculated. Chi-square test was used for categorical variables and $p$ value was calculated for nasal smear eosinophilia and high IgE levels. Sensitivity, specificity, PPV and NPV of the two tests were calculated, keeping $p$ value $<0.05$.

A total of 221 patients were included in the study, out of which $121(54.8 \%)$ patients were in group 1 and 100 (45.2\%) were included in group 2. Group 1 patients were labelled as allergic rhinitis, while group 2 patients were labeled as controls. Clinical features, history and typical examination findings of group 1 and group 2 are listed in Tablel.

Table I: Comparative frequency of symptoms in both groups.
\begin{tabular}{|l|c|c|}
\hline $\begin{array}{l}\text { Variable symptoms/ presenting } \\
\text { complaints }\end{array}$ & $\begin{array}{c}\text { Group 1 } \\
\text { Frequency (n) } \\
\mathbf{1 2 1}(\mathbf{5 4 . 8 \% )}\end{array}$ & $\begin{array}{c}\text { Group 2 } \\
\text { Frequency (n) } \\
\mathbf{1 0 0}(\mathbf{4 5 . 2} \%)\end{array}$ \\
\hline Rhinorrhea & $121(100 \%)$ & $92(92 \%)$ \\
\hline Sneezing & $111(91.7 \%)$ & $12(12 \%)$ \\
\hline Nasal obstruction & $76(62.8 \%)$ & $24(24 \%)$ \\
\hline Nasal congestion & $57(47.1 \%)$ & $15(15 \%)$ \\
\hline Bluish tinge on anterior rhinoscopy & $88(72.7 \%)$ & \\
\hline Allergic salute & $51(42.1 \%)$ & \\
\hline Hyposmia & $63(52.1 \%)$ & $14(14 \%)$ \\
\hline Co-existent asthma & $50(41.3 \%)$ & \\
\hline
\end{tabular}

\section{RESULTS}

The mean age of patients was $25.26 \pm 8.83$ years ranging from 5 to 45 years in group 1 . In group 2 , mean age was $24.86 \pm 7.37$ years ranging from 8 to 41 years. Sixty-eight patients (56.2\%) were males and 53 (43.8\%) were females in group 1; and in group 2, 51 (51\%) were males and 49 (49\%) were females.

Mean IgE level was $493.30 \pm 258.55 \mathrm{IU} / \mathrm{ml}$ in group 1 and 228.12 $\pm 81.85 \mathrm{lU} / \mathrm{ml}$ in group 2 . The mean difference in both groups was statistically significant with $p<0.001$. The mean eosinophil count was $7.91 \pm 4.60$ in group 1 and $3.50 \pm 3.05$ in group 2 with statistically significant mean difference in both groups $(p<0.001)$.

Nasal smear for eosinophils was positive (more than 3 cells per high power field) in 91/121 (75.2\%) patients in group 1; and in $26 / 100(26 \%)$ patients in group $2(p<0.001)$. High IgE levels were positive in 89/121 (73.6\%) patients and 19/100 (19\%) in group 2 ( $p<0.001)$.

Sensitivity, specificity, PPV, and NPV of nasal smear eosinophilia was $77.8 \%, 71.2 \%, 75.2 \%$, and $74 \%$, respectively. Same values for serum IgE levels were $82.4 \%, 71.7 \%, 73.6 \%$, and $81 \%$, respectively.

\section{DISCUSSION}

This study included 121 patients diagnosed with allergic rhinitis on the basis of history and typical examination findings; and confirmed on skin prick tests. The mean age of the patients, diagnosed with allergic rhinitis in this study was $25.26 \pm 8.83$ years, which is comparable to study of Osisi et al., conducted in North Western Nigeria. ${ }^{10}$ Allergic rhinitis patients can present at any age without gender predilection. However, it is said that 
majority of patients present during adolescence. This study findings are comparable with the study by Cazzoletti et al., which concluded that AR peaks in adulthood. ${ }^{11}$

This study showed that the major presenting symptom was rhinorrhea in $100 \%$ and sneezing in $91.7 \%$ patients followed by nasal obstruction (62.8\%), congestion (47.1\%), and hyposmia (52.1\%) patients. Lakhani et al. reported that nasal manifestations are hallmark of AR. ${ }^{12}$ A study conducted in 2019 also revealed that nasal manifestations are major presenting symptoms followed by itching in nose and nasal congestion in AR, which is comparable to this study. ${ }^{13,14}$ In this study, bluish tinged nasal mucosa was seen in $72.7 \%$, and allergic salute in $42.1 \%$ patients. Typical physical findings for AR include pale, bluish tinged mucosa with boggy inferior turbinates on anterior rhinoscopy, clear watery secretions and allergic salute. ${ }^{15}$

Early diagnosis of AR is necessary for proper treatment to improve quality of life and avoid potential complications. ${ }^{16} \mathrm{~A}$ variety of laboratory investigations are in clinical use to diagnose or confirm diagnosis in a suspected patient of AR including nasal smear for eosinophils, peripheral smear for eosinophils, skin prick tests and lgE levels (total and specific). ${ }^{17}$

Nasal smear eosinophilia and serum IgE levels are considered to be simple, economical and reliable investigations to diagnose AR. This study showed nasal smear eosinophilia and high IgE levels in patients of AR; and these findings are comparable with study by Sharma conducted in $2018 .{ }^{18}$ In the present study, the difference in mean eosinophil count between the AR and control group was statistically significant with $p<0.001$; and this study findings are consistent with study of Cingi C, conducted in 2017. ${ }^{9}$ In this study sensitivity, specificity, PPV, and NPV of nasal smear eosinophilia was $77.8 \%, 71.2 \%, 75.2 \%$, and $74 \%$, respectively. Study by Nurkic et al. revealed that nasal smear eosinophilia is a more specific test having relatively high specificity in contrast to sensitivity, which is not consistent with this study findings; whereas, study by Mostafa et al. revealed sensitivity and specificity similar to the present study. ${ }^{2,19}$ This difference can be attributed to differences in characteristics of study population. The present study findings show that nasal smear for eosinophils is a reliable and non-invasive diagnostic test for AR; and this finding is comparableto study of Berkiten etal. ${ }^{20}$

The mean IgE level in group 1 was $493.30 \pm 258.55 \mathrm{IU} / \mathrm{ml}$ and in group 2 was $228.12 \pm 81.85 \mathrm{IU} / \mathrm{ml}$; and mean difference in both groups was statistically significant with $p<0.001$. These results are comparable to study by Ansari et al. ${ }^{21}$. In this study sensitivity, specificity, PPV and NPV of serum IgE was $82.4 \%, 71.7 \%$, $73.6 \%$ and $81 \%$, respectively, revealing that serum IgE level is reliable, and a simple investigation for diagnosing AR. Findings of this study are consistent with the findings reported by Chung. ${ }^{22}$

\section{CONCLUSION}

To diagnose allergic rhinitis, both serum IgE levels and nasal smear eosinophilia are helpful. However, serum IgE level has better sensitivity and higher negative predictive value than smear eosinophilia. Specificity of both the tests is comparable.

\section{ETHICALAPPROVAL:}

This study was approved by Institutional Review Board, King Edward Medical University, Lahore, Pakistan (Approval Letter No. 334/RC/KEMU, dated 12/05//2020).

\section{PATIENTS'CONSENT:}

Informed consents were obtained from all patients to publish the data.

\section{CONFLICT OF INTEREST:}

Authors declared no conflict of interest.

\section{AUTHORS'CONTRIBUTION:}

NA: Manuscript writing.

SQ: Data collection.

KMC: Data interpretation.

NR: Critical review.

SA: Data analysis.

AR: Critical review

\section{REFERENCES}

1. Watts AM, Cripps AW, West NP, Cox AJ. Modulation of allergic inflammation in the nasal mucosa of allergic rhinitis sufferers with topical pharmaceutical agents. Front Pharmacol 2019; 10:294. doi: 10.3389/fphar.2019.00294.

2. Mostafa HS, Qotb M, Hussein MA, Hussein A. Allergic rhinitis diagnosis: skin-prick test versus laboratory diagnostic methods. Egypt J Otolaryngol 2019; 35(3): 262-8.

3. Said SA, Mchembe MD, Chalya PL, Rambau P, Gilyoma JM. Allergic rhinitis and its associated co-morbidities at Bugando Medical Centre in Northwestern Tanzania; A prospective review of 190 cases. BMC Ear Nose Throat Disord 2012; 12:13. doi: 10.1186/1472-6815-12-13

4. Demir MG. Comparison of $1 \alpha-25$-dihydroxyvitamin D3 and IgE Levels between Allergic Rhinitis Patients and Healthy People. Int Arch Otorhinolaryngol 2018; 22(4): 428-31. doi: 10.1055/s-0038-1649492.

5. Varshney J, Varshney H. Allergic rhinitis: An overview. Indian J Otolaryngol Head Neck Surg 2015; 67(2):143-9. doi: 10.1007/s12070-015-0828-5.

6. Greiwe JC, Bernstein JA. Allergic and mixed rhinitis: diagnosis and natural evolution. J Clin Med 2019; 8(11): 2019. doi: 10.3390/jcm8112019.

7. Ibekwe PU, Ibekwe TS. Skin prick test analysis in allergic rhinitis patients: A preliminary study in abuja, nigeria. J Allergy (Cairo) 2016; 2016: 3219104. doi: 10.1155/ 2016/3219104.

8. Seidman MD, Gurgel RK, Lin SY, Schwartz SR, Baroody FM, Bonner JR, et al. Guideline otolaryngology development group. AAO-HNSF. Clinical practice guideline: Allergic rhinitis. Otolaryngol Head Neck Surg 2015; 152(1 Suppl):S1-43. doi: 10.1177/0194599814561600.

9. Cingi C, Gevaert P, Mösges R, Rondon C, Hox V, Rudenko M et al. Multi-morbidities of allergic rhinitis in adults: European academy of allergy and clinical immunology task force report. Clin Transl Allergy 2017; 7:17. doi: 10.1186/ 


\section{s13601-017-0153-z.}

10. Osisi K, Iseh KR, Ndodo ND, Inoh MI, Yikawe SS, Solomon $\mathrm{JH}$, et al. Serum IgE of allergic rhinitis (AR) with or without Asthma in Sokoto, North Western Nigeria. IOSR J Dental Med Sci 2017; 16(6):85-9.

11. Cazzoletti L, Ferrari M, Olivieri M. The gender, age and risk factor distribution differs in self-reported allergic and non-allergic rhinitis: A cross-sectional population-based study. Allergy Asthma Clin Immunol 2015; 11:36. doi: 10.1186/s13223-015-0101-1.

12. Lakhani $N$, North M, Ellis AK. Clinical manifestations of allergic rhinitis. J Aller Ther 2012; S5:007. DOI: 10.4172/ 2155-6121.S5-007.

13. Rudrappa S, Kumar R, Kumar V. Study of eosinophil count in nasal smear and peripheral blood smear in children with allergic rhinitis. Int J Contemp Pediatr 2019; 6:1158-62.

14. Saleem T, Khalid U, Sherwani UR, Ghaffar S. Clinical profile, outcomes and improvement in symptoms and productivity in rhinitic patients in Karachi, Pakistan. BMC Ear Nose Throat Disord 2009; 9:12. doi: 10.1186/1472-6815-9-12.

15. Small P, Keith PK, Kim H. Allergic rhinitis. Allergy Asthma Clin Immunol 2018; 51(2).

16. Kalmarzi RN, Khazaei Z, Shahsavar J, Gharibi F, Tavakol M, Khazaei $S$, et al. The impact of allergic rhinitis on quality of life: a study in western Iran. Biomedical Research and
Therapy 2017; 4(9):1629-37.

17. Krouse HJ, Krouse JH. Allergic rhinitis: Diagnosis through management. Nurse Practitioner 2014; 39(4):20-8; quiz 29.

18. Sharma M, Khaitan T, Raman S, Jain R, Kabiraj A. Determination of serum $\lg E$ and eosinophils as a diagnostic indicator in allergic rhinitis. Indian J Otolaryngol Head Neck Surg 2019; 71(Suppl 3):1957-61. doi: 10.1007/s12070-018-1383-7.

19. Nurkic J, Ahmad MA, Arifhodzic N, Jusufovic E. The role of target organ diagnostic approach in seasonal allergic rhinitis: Nasal smear eosinophils. Materia Socio-medica 2016; 28(2):125-8. doi: 10.5455/msm.2016.28.125-128.

20. Berkiten G, Aydoğdu I, Kumral TL, Saltürk Z, Uyar Y, Arslanoğlu A, et al. Nasal eosinophilia in nasal smears of patients with persistent and intermittent allergic rhinitis. J Laryngol Otol 2018; 132(11):1018-21. doi: 10.1017/ S0022215118001986.

21. Ansari SF, Memon M, Brohi N. Vitamin D and serum immunoglobulin $E$ levels in allergic rhinitis: A case-control study from Pakistan. Cureus 2019; 11(12):e6495. doi: 10.7759/cureus.6495.

22. Chung D, Park KT, Yarlagadda B, Davis E, Platt M. The significance of serum total immunoglobulin $E$ for in vitrodiagnosis of allergic rhinitis. Int Forum Allergy Rhinol 2014; 4(1):56-60. doi: 10.1002/alr.21240. 